Mujeres católicas y Estado en torno a la pobreza y la infancia: viejas y nuevas intervenciones en la provincia de Buenos Aires, 1913-1926

Yolanda de Paz Trueba

Anuario No 33 / ISSN 1853-8835 / 2020

http://anuariodehistoria.unr.edu.ar/ojs/index.php/Anuario/index

\title{
Mujeres católicas y Estado en torno a la pobreza y la infancia: viejas y nuevas intervenciones en la provincia de Buenos Aires, 1913-1926
}

\author{
Catholic women and the State around poverty and \\ childhood: old and new interventions in the province of \\ Buenos Aires, 1913-1926
}

YOLANDA DE PAZ TRUEBA

Instituto de Geografia, Historia y Ciencias Sociales, Consejo Nacional de Investigaciones Científicas y Técnicas, Universidad Nacional del Centro (Argentina) yolidepaz@gmail.com

RESUMEN

En Argentina, el desarrollo económico que desde fines del siglo XIX había permitido cierta holgura para algunos sectores sociales, excluyó a muchos, lo que se hizo particularmente evidente en el contexto de la Primera Guerra Mundial y la crisis económica por la que atravesó el país en esos años. Este artículo se pregunta si en un marco de inquietudes renovadas se asistió a un cambio de rumbo en las acciones sobre la infancia pobre. El trabajo propone que aunque las preocupaciones por este colectivo encontraron un eco ampliado por parte de la opinión pública y algunos sectores del arco político, en los espacios locales analizados, las prácticas concretas siguieron estando atadas a la labor benéfica católica gestionada por mujeres. En ellos, las acciones públicas más novedosas solo se orientaron a mitigar la pobreza de las clases trabajadoras.

Palabras clave: Infancia; Pobreza; Intervenciones; Mujeres; Estado

ABSTRACT

In Argentina, the economic development that had allowed some slack for some social sectors since the end of the 19th century, excluded many, which became particularly evident in the context of the First World War and the economic crisis that the country went through in those years. This article asks whether, in a framework of renewed concerns, there was a change of course in actions on poor childhood. The work proposes that although concerns about this group found an extended echo by public opinion and

Esta obra está sujeta a la Licencia Reconocimiento-NoComercial-Compartirlgual 4.0 Internacional de Creative Commons. http://creativecommons.org/licenses/by-nc-sa/4.0/ 
some sectors of the political arc, in the local spaces analyzed, concrete practices continued to be tied to Catholic charity work managed by women. In them, the most innovative public actions were only aimed at mitigating the poverty of the working classes.

Keywords: Childhood; Poverty; Interventions; Women; State

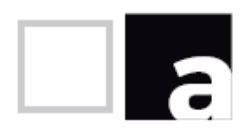

\section{Introducción}

A mediados de la segunda década del siglo XX, múltiples discursos hacían referencia a la pobreza y las dificultades económicas por las que atravesaban la provincia de Buenos Aires y sus pueblos. El desarrollo económico que desde fines del siglo XIX habia permitido una vida de bonanza para algunos sectores sociales y cierto ascenso para otros, había también excluido a muchos. Aunque el éxito generalizado había opacado esas exclusiones, la crisis se hizo imposible de soslayar recién ante la inflexión económica y el cambio de rumbo que el conflicto bélico de 1914 trajo aparejados. En este marco, se vieron acrecentadas las preocupaciones que por entonces representaba la infancia mendicante y abandonada, aquella que no tenía familia y los que aun teniéndola vagaban por las calles de los pueblos de la provincia en cantidades considerables.

Por ello, la pregunta que guía este artículo es si, en un contexto de preocupaciones renovadas y atentos a una insistencia discursiva que planteaba la necesidad de dar respuestas definitivas a problemas que se señalaban como responsabilidad de la familia y más novedosamente del Estado, es posible vislumbrar un cambio de rumbo en las intervenciones sobre los niños y niñas pobres.

En términos generales puede decirse que no hace tanto que la historiografia argentina se interroga por el Estado y las políticas sociales. Acaso la crisis de los años $90 \mathrm{y}$ 2000, la significativa retirada del mismo y la privatización de muchas de sus funciones con su correlato de aumento de las desigualdades, fue un punto de partida para reparar en su proceso de construcción histórica y en la manera en que estas habian sido resueltas en el pasado (Lvovich y Suriano, 2006; Moreyra, 2009).

\section{anuario.}


En este sentido, una línea de investigación prolífica ha mostrado de qué modo en los tramos finales del siglo XIX y comienzos del XX fueron las instituciones de la sociedad civil, mayormente lideradas por mujeres, las que desarrollaron una amplia tarea asistencial en momentos en que el Estado en formación no se hacía cargo de esas necesidades (Dalla Corte y Piacenza, 2006; Bonaudo, 2006; Moreyra, 2009; Eraso, 2009; de Paz Trueba, 2010; Billorou, 2010; Guy, 2011; Pita, 2012; Bracamonte, 2012, entre otros) ${ }^{1}$.

Por otro lado, los estudios que retoman diversos costados del catolicismo social, nos han provisto de insumos que permiten entender con mayor complejidad el lugar que las mujeres encontraron en las instituciones de beneficencia y los motivos por los que fueron interpeladas para incrementar su accionar justo en el mismo momento en que desde otros ámbitos se insistía en la necesidad de una mayor intervención estatal (Mauro, 2014; Toussonian, 2015; Lida, 2015; Vidal, 2016; Bracamonte, 2017).

Otra linea de trabajos en expansión, es aquella que ha posado su mirada específicamente en los menores de edad 2 . Estas investigaciones, han contribuido a pensar las instituciones y los actores que repararon en los niños, niñas y jóvenes y sus propias problemáticas relativas a la educación, la salud, la familia, los mundos laborales, las políticas públicas de control y represión y las acciones de asociaciones de beneficencia entre otras (Aversa, 2015; Fredeinraij, 2015; Allemandi, 2017; Zapiola, 2019).

Este artículo, debe mucho a todos esos desarrollos que pensaron la infancia, las instituciones de asistencia en su relación ambivalente con el Estado, y a las mujeres en ellas. Pero, atento a un momento histórico signado por una crisis económica en parte generada por los coletazos de la Primera Guerra Mundial sobre la economía argentina y nuevos reclamos al Estado, pretende aportar al estudio de las continuidades y los deslizamientos en las politicas sociales hacia la infancia3. Haciendo hincapié en los matices que tomaron las interpelaciones al Estado por parte de la opinión pública ${ }^{4}$ en un marco de renovadas demandas, se busca dar cuenta del

\footnotetext{
1 Eran de variado tipo e incluían la ayuda a los más pobres proveyéndolos de ropa, calzado, alimentos, medicamentos, el pago del alquiler, y en otros casos una asistencia más orgánica como la que brindaban las instituciones que alojaban y educaban a niñas, niños y jóvenes huérfana/os y/o abandonada/os, madres con niños por nacer, hospitales de caridad, asilos para pobres, etc.

2 No desconocemos las diferencias de categorias como menor, niños e infancia (Zapiola, 2019), pero se usan como sinónimos porque así lo reflejan las fuentes y no afectan al análisis realizado.

${ }^{3}$ Las politicas sociales se entienden aquí como las intervenciones destinadas a mitigar las desigualdades que el desarrollo económico de comienzos de siglo produjo en Argentina. Desde esta perspectiva estas comprendieron tanto las gestadas por actores estatales como, sobre todo, las emanadas de actores privados en interacción con los públicos.

4 Entiendo por opinión pública las apreciaciones generales que sobre los temas aludidos manifestaba la sociedad en general y algunos individuos (intelectuales y politicos) en particular a través de la prensa, las fuentes legislativas y otros documentos oficiales que se usan en este trabajo.
}

\section{anuario.}


lugar del Estado y de las mujeres en las acciones llevadas adelante en relación a la pobreza y a la infancia. En este sentido, se analizan tanto el ámbito provincial como el municipal, en los que confluyeron demandas pero se diferenciaron, sostengo, las medidas (privadas y estatales) puestas en práctica.

Si bien no desconocemos que, como plantea María José Ortiz Bergia (2009), hay una continuidad en materia de políticas sociales entre la época de entreguerras y el peronismo de los años cuarenta, se asume que debemos estar más atentos a los matices que en estos aspectos presentan los años previos, especialmente hacia y durante la década del 20, que han sido escasamente estudiados aun. Por ello, este artículo pretende ser un aporte en este sentido, buscando dar cuenta de las singularidades, continuidades y pequeños desplazamientos que se observan entre 1913, momento en que los signos de la crisis económica y social se tornaron evidentes y las demandas al Estado comenzaron a incrementarse y diversificarse, y los años 20, cuando en la región centro y sur de la provincia grupos de mujeres laicas con sólidos vínculos con la Iglesia católica fundaron nuevas instituciones de protección destinadas a niños y niñas y modificaron el rumbo de otras existentes, de cara a responder a necesidades que, solo a nivel provincial y de manera incipiente, el Estado tomó en sus manos.

A través de un conjunto heterogéneo de fuentes 5 , se busca hacer un recorrido por los requerimientos que desde mediados de la década del 10, se entablaron en materia de infancia, tanto desde las páginas de la prensa como por parte de sujetos políticos que actuaron en el ámbito legislativo municipal y provincial. Por medio de estos planteos se busca ver cómo una diversidad de actores pensaba al Estado en materia social y qué esperaban particularmente en lo relativo a la infancia pobre, en un contexto inédito en el que se mixturaron la crisis económica y la conflictividad laboral. También, y atendiendo a los matices en el ámbito provincial y local, se busca reparar en las respuestas brindadas y en los actores que intervinieron para resolver los problemas que se presentaron desde una zona particular: el centro de la provincia de Buenos Aires, buscando complejizar esos discursos y aun esas acciones analizando su puesta en práctica en ese espacio concreto 6.

En sintesis y por lo antes dicho, las páginas siguientes parten del presupuesto que las preocupaciones por la infancia pobre encontraron un eco ampliado por parte de la opinión pública y algunos sectores del arco político en los que individualmente se pueden observar algunas mutaciones en la manera de entender las funciones estatales. No obstante esto, se sostiene que mientras en el ámbito provincial se

\footnotetext{
5 Prensa local y provincial, discursos de funcionarios de la época y actas de sesiones municipales y legislativas de la provincia de Buenos Aires.

${ }^{6} \mathrm{El}$ texto hace foco especialmente en las localidades de Azul y Tandil y su amplia zona rural circundante. Una región que presenta aristas interesantes para abordar estas preocupaciones desde que fue una de los que más se benefició de la expansión y modernización económica, social y cultural de fines del siglo XIX y comienzos del XX, pero donde también se hicieron sentir con fuerza las carencias ante la crisis económica, alcanzado los conflictos laborales matices violentos.
} 
avanzó en nuevas intervenciones de carácter netamente estatal, en los espacios locales analizados las medidas concretas siguieron estando atadas a la práctica benéfica católica gestionada por mujeres. En ellos, las acciones públicas más novedosas solo se orientaron a mitigar la pobreza de las clases trabajadoras.

\section{La pobreza en un contexto de crisis: mendicidad y desigualdades en aumento}

A fines del siglo XIX Argentina había crecido a niveles exponenciales, de la mano de su conexión comercial con el mercado internacional. Ese crecimiento se vio por la misma época acompañado por un incipiente desarrollo industrial destinado mayormente al consumo interno.

Si bien las ciudades de Buenos Aires y La Plata, se habian destacado en este sentido, sus efectos se hicieron sentir más allá de sus fronteras, como en los pueblos pujantes del centro de la provincia que en su tránsito a la vida de ciudad, acompañaron desde el ámbito urbano la expansión agropecuaria. Además, en el caso de Tandil específicamente, la industria de la piedra dio impulso a una economía local con proyecciones nacionales.

Las bases de ese crecimiento estaban dadas sobre una estructura que tenía sus propias dificultades y limitaciones, pero que no se pusieron de manifiesto hasta pasada la primera década del siglo XX y especialmente tras el estallido de la Primera Guerra Mundial.

Es cierto que esta no significó el origen de los problemas económicos y financieros que desde hacía un tiempo venían acuciando a la provincia de Buenos Aires. No obstante, el conflicto mundial los potenció y generó otros. Una de las aristas más evidentes de esa economía en crisis eran la pobreza y la mendicidad que se exhibian diariamente en las calles y que la prensa denunciaba insistentemente. ${ }^{7}$ Pero además, cuando los que mendigaban eran menores de edad, las inquietudes se conectaban con otras preocupaciones que también eran de larga data: las de la los niños y niñas pobres y/o abandonados y la lábil frontera que los separaba de la delincuencia. Una preocupación compartida por médicos, abogados, intelectuales y legisladores que veían en riesgo el futuro de la nación, desvelos que no fueron locales ni aún nacionales: formaron parte de una matriz de ideas que trascendió las fronteras y atravesó todo el siglo XX. Esto configuró un movimiento internacional que cuajó en algunos emprendimientos (como el Primer Congreso Panamericano del Niño celebrado en 1916) incitados por científicos y profesionales de distintos Estados de

\footnotetext{
7 Algo que excedía a la provincia de Buenos Aires como ha mostrado Fernando Remedi (2017 y 2019) para Córdoba en un período similar.
} 
la región, para generar un mapa de conocimiento sobre la infancia americana (Guy, 2011; Rojas Novoa, 2018).

Todas esas voces que con intereses diversos realizaron diagnósticos y reflexionaron en torno a las soluciones puestas en marcha y a las que se deberian implementar, reclamaron una mayor intervención del Estado para proteger a ciertos sectores vulnerables de esa infancia. Sacarlos de la calle y crear espacios donde alojarlos, era señalado como la mejor manera de reformarlos y "lanzarlos" a la sociedad como ciudadanos útiles a la misma. Sin embargo, más allá de la insistencia, los espacios estatales fueron escasos, cuando no inexistentes, en el interior de la provincia de Buenos Aires 8 .

Los reclamos de la prensa local y provincial en torno a la represión del vagabundeo y la vagancia (especialmente infantil), preceden con mucho al periodo que aquí se analiza9. Pero desde 1913 y sobre todo en el contexto de la conflagración mundial, comenzó a aludirse de manera profusa al incremento que había experimentado no solo el vagabundeo, sino también la mendicidad callejera ${ }^{10}$. Algo que, según sostiene Remedi (2017), molestaba no solo por el aumento real de la misma sino por la nueva sensibilidad que por esos años habria despertado el fenómeno.

Muchas de esas denuncias afirmaban que la crisis económica causada por el conflicto bélico, el desempleo creciente y la suba de precios de los productos de primera necesidad, habian multiplicado la magnitud de estas manifestaciones. ${ }^{11} \mathrm{~A}$ la pobreza estructural se agregaba ahora la presencia de nuevos pobres, aquellos que habian experimentado cierto bienestar de la mano del crecimiento de las incipientes industrias y que pasaron a engrosar las filas de la desocupación estacional. Si bien no se advierte en la óptica periodística un cambio significativo en la manera de entender la acción del Estado, sí es factible sugerir una interpelación creciente al mismo y un desplazamiento en su concepción de la responsabilidad social sobre la mendicidad: esta no era solo una cuestión moral, sino que también respondía ahora a causas socioeconómicas que excedían la voluntad de los menesterosos ${ }^{12}$.

Como señalé, según pasaban los años estas denuncias se hicieron más insistentes, especialmente en torno al incremento de una de sus caras más inquietantes para los

\footnotetext{
8 Una excepción se dio en Bahía Blanca, donde el municipio creó en 1918 un Patronato de Menores, tema de relevancia que aún no ha sido estudiado en profundidad.

9 El Imparcial, Azul, Niños vagos, 24/1/1901. El Día, La Plata, Los niños vagos, 28/9/1903. El Eco de Tandil, Tandil, Tareas escolares, 27/2/1910; Vagos y vaguitos, 28/4/1912, entre otros.

10 El Orden, Azul, Incremento de la mendicidad, 22/3/1914 y El Día, La Plata, La mendicidad infantil, 24/1/1917, entre otros.

11 El Eco de Tandil, Tandil, Un peligro, 15/4/1917. El Ciudadano, Azul, La vagancia y el robo, $26 / 7 / 1917$.

12 Algo similar sostiene Remedi (2017 y 2019) al estudiar la prensa cordobesa del periodo, si bien desde otra perspectiva pues sus intereses analíticos se orientan a la reconstrucción de las imágenes sobre la mendicidad.
} 
contemporáneos: “(...) el triste espectáculo de la infancia marchitando

sus encantos y sus purezas en la mendicidad". ${ }^{13}$ Por ello, la prensa reclamaba nuevas intervenciones, que en muchas ocasiones no eran tan novedosas. En general se trataba de medidas de carácter dual donde la demanda de represión se mixturaba con la necesidad de brindar amparo. Así como El Ciudadano de Azul reclamaba “(...) una acción conjunta para contrarrestar estos malos hábitos infantiles con el concurso de la policía y las autoridades municipales (...)"14, en ocasiones también se clamaba por nuevas medidas de protección.

No obstante las continuidades señaladas, en esos discursos es posible observar un clima de época que lentamente y con ambivalencias, va cambiando en relación a la responsabilidad del Estado por la cuestión social de los menores de edad. ${ }^{15}$. Así, decía El Ciudadano de Azul que buscaban llamar la atención de las autoridades ya que en ellas recaía la responsabilidad última de sacar de las calles a los niños y niñas ${ }^{16}$ pero sostenía también que esos pequeños debian ser resguardados

“(...) por las autoridades y las sociedades de beneficencia que felizmente las hay aqui en notoria abundancia. Estas sociedades que tanto reciben de nuestra sociedad a título de cooperación a su obra caritativa, deben agregar a sus protegidos la desgraciada legión que nos ocupa (...)”,

en relación a estos chicos que aun teniendo familia, estaban abandonados o no contaban con una guía fuerte que los preparara como hombres y mujeres de bien. ${ }^{17}$ Sumado a esto, se incitaba aunque de manera incipiente, a innovar en los métodos e incorporar otras maneras de resolver

“(..) $\sin$ necesidad de exigírseles el enclaustramiento a que tan afanadas se muestran[ las instituciones de beneficencia](...)es preciso hacer algo en este sentido; nuevas iniciativas deben surgir hasta dar con el remedio eficaz conducente a prescribir de nuestra ciudad el afligente cuadro que esbozamos" 18 .

La prensa provincial coincidia también en que la manera hallada hasta el momento para atender a la mendicidad infantil había sido inadecuada, puesto que no era suficiente con vestir a los menores necesitados y darles de comer, como mayormente

\footnotetext{
13 El Eco de Tandil, Tandil, Mal que se agiganta, 13/1/1918. También El Día, La Plata, La mendicidad infantil, 24/1/1917, cit. y El Eco de Tandil, Tandil, Por la calle. Mendicidad, 18/5/1922.

14 El Ciudadano, Azul, Pro infancia desvalida, 2/11/1917.

$15 \mathrm{Si}$ bien las denuncias de la prensa no eran ingenuas ya que en tanto actor político defendió o denostó las posiciones de alguna de las facciones en que se dividian los partidos que dominaban el escenario del momento (radicales y conservadores), el tenor de los reclamos era similar en medios de prensa de orientaciones politicas diversas como los analizados y los excedía.

16 El Ciudadano, Azul, La vagancia, 20/8/1917.

17 El Ciudadano, Azul, Mendicidad infantil, 28/5/1917.

18 Idem.
} 
se había hecho, con una confianza extrema en el "diletantismo caritativo" privado 19. La formación técnica y moral debía ser encarada desde el Estado provincial y municipal, los que además debian gestionar de manera más articulada el otorgamiento de subsidios, para maximizar el uso de esos recursos. En el espíritu de este discurso que mantuvo el diario página tras página, estaba el recoger menores considerados vagos para internarlos en asilos talleres así como tomar medidas destinadas a prevenir entre las familias pobres siendo el gobierno quien debía actuar en ese sentido ${ }^{20}$. A través de la intervención sobre los más pequeños, se lograba así además de formar buenos ciudadanos, moralizar a las familias de clases populares del presente, que ponían en jaque las pretensiones de progreso.

Sin embargo, no debemos ver en estas reflexiones cambios radicales sino más bien pequeños desplazamientos que combinaban un requerimiento de acciones benéficas privadas con otras de carácter estatal, subrayando con mayor insistencia la responsabilidad política en la solución de los males que el presente mostraba. Al mismo tiempo, las acciones de socorro de mayor envergadura especialmente si eran de carácter asilar, se seguían pensando en estrecha relación con las asociaciones benéficas existentes o nuevas ${ }^{21}$.

En sintesis, a lo largo del periodo estudiado, la prensa local y provincial es enfática y recurrente en torno a la cuestión de la pobreza, la crisis y el consecuente aumento de la mendicidad infantil. Al mismo tiempo y en sintonía con preocupaciones que exceden el ámbito local y aun el nacional, la infancia y su protección eran un tema central en esos discursos que conforme pasaban los años, se mantenían. Y si bien hay una interpelación directa al Estado especialmente en relación al control social y a la necesidad de reprimir acciones y despliegues públicos de mendicidad y pobreza, paulatinamente, va colándose también en algunos de esos reclamos, una manera de entender al Estado como responsable de brindar mayor protección. Sin embargo, y especialmente en materia de infancia, esa acción estatal sigue siendo pensada en conjunto con las asociaciones de beneficencia locales.

\section{La labor de los elencos politicos estatales de nivel municipal por la infancia y la pobreza}

En función del contexto antes descrito, hacia 1913 y ante una situación económica que comenzaba a mostrar signos de agotamiento, los sucesivos gobernadores de la provincia se vieron ante la dificultad de equilibrar los gastos, llegando incluso a

\footnotetext{
19 El Día, La Plata, La mendicidad infantil, 24/1/1917, cit., y Niños pobres, 6/6/1916.

20 El Día, La Plata, Idem; Depósito de menores, 26/1/1917, cit.; Problemas sociales. La mendicidad infantil en La Plata, 29/1/1917; Los niños abandonados. Problemas sin solución seria, 1/3/1917, entre otros.

21 El Eco de Tandil, Tandil, Mal que se agiganta, 13/1/1918, cit. y El Día, La Plata, Los niños desamparados, 29/3/1918.
} 
disminuir los sueldos de los empleados públicos estatales y reducir puestos de trabajo en el Estado 22 .

En los espacios locales estudiados por su parte, los presupuestos municipales se vieron exigidos por demandas para desarrollar obras de infraestructura en ciudades que crecian rápidamente cuando la crisis económica complicó la recaudación impositiva. Por ello, casi paradójicamente, muchas medidas de los funcionarios a cargo de la gestión debieron procurar el alivio de los contribuyentes ajustando los gastos programados en relación a ingresos en caída.

El caso de Azul fue más complejo dado que las reiteradas acefalías municipales a que se había visto sometida la comuna a causa de la dinámica política, habían estancado el funcionamiento del Estado local en materia administrativa ${ }^{23}$. Tal fue así que por esos años, el intendente Ángel Pintos mostró su preocupación por la cuestión impositiva y se hizo eco de la compleja coyuntura por la que debía transitar su comunidad. Por ello pedía al Concejo Deliberante autorización para reducir deudas de impuestos municipales a contribuyentes que fueran dueños de una sola propiedad. ${ }^{24} \mathrm{~A}$ fines de ese mismo año sugirió la posibilidad de reducir algunos gravámenes, en este caso el derecho de sisa a aquellos “(...) humildes trabajadores que se dedican al expendio a domicilio de artículos de primera necesidad (...) procurando con esta medida abaratar en lo posible los mencionados artículos". Aunaba con esta iniciativa, la protección para vendedores y consumidores de esos productos que eran también los que más se veían afectados “(...) por la difícil situación que creaba en el país la Conflagración Europea”, según el mismo Pintos afirmaba en otra ocasión 25 .

Si los gobernadores debian atender a equilibrar las finanzas provinciales, los intendentes tuvieron que lidiar no solo con presupuestos colapsados por las razones antes dichas sino también con la responsabilidad de reservar alguna porción del mismo para brindar socorros a los pobres que según denunciaba la prensa, desfilaban mendigando por las ciudades y pueblos en una magnitud en constante

\footnotetext{
22 Diario de Sesiones de la provincia de Buenos Aires, Año 1913, Cámara de Senadores, La Plata, Taller de impresiones oficiales, 1913, p. 20. Ibidem, Año 1915, p. 10.

23 Los desacuerdos entre las distintas facciones politicas llevaron a cuestionar los resultados de las elecciones y a que la parte opositora las impugnara ante la justicia. Mientras, distintos comisionados gobernaban en representación del poder provincial. Esto sucedió desde 1900 y especialmente entre 1906 y 1916. Un breve interregno se dio en 1911, llegando por un corto período a la intendencia Manuel Castellar, quien en apenas 9 meses hizo obras de consideración como el inicio de la construcción del Mercado Municipal, ensanche de caminos, arreglos de calles, entre otros. (Fuentes, 2016). Desde el año 1916, cuando se normalizó la situación institucional la necesidad de mejorar la recaudación de impuestos y la vida administrativa fue recurrente en las discusiones de los concejales. Archivo del Concejo Deliberante de Azul (en adelante ACDA), Libro de Actas (27/11/1911 al 2/11/1919), $18 / 11 / 1916$, f. 53 y 3/3/1917, f. 93 entre otras.

24 Ibidem, 16/9/1916, f. 26.

25 Ibidem, 6/12/1916, f.67 y 3/3/1917, f. 93.
} 
crecimiento. Se vieron así frente a la necesidad de desarrollar maneras novedosas de atender a los viejos contingentes de pobres así como a los nuevos integrantes de sus filas.

Por ello, a diferencia de épocas anteriores, gestionar una baja de precios de productos de primera necesidad y una accesibilidad mayor a ellos para los sectores empobrecidos, estaba en el espíritu de lo que Pintos procuraba en Azul y Santamarina y sus sucesores en Tandil.

Como se dijo, antes del estallido de la Guerra se habian empezado a notar ciertas dificultades en estos aspectos, y la pobreza parecía extenderse. Por ello, ya en 1913 el Concejo Deliberante de Tandil había promovido la toma de algunas medidas para “(...) abaratar la carne de consumo en la población (...)"26, ya que como decía Santamarina tiempo después

"Uno de los problemas que por su importancia más preocupa a los poderes públicos es actualmente el grado de carestía a que han llegado los articulos alimenticios en general y en particular aquellos considerados de primera necesidad para el abastecimiento del hogar (...)”.

Por ello, había hecho gestiones con el gremio de panaderos y la gerencia del Molino del Sud, para obtener una reducción en el precio de la harina y del pan. Al mismo tiempo, mencionaba la intención de establecer ferias francas para proveer alimentos a menor costo 27 , medida que también se buscó tomar en Azul años despues ${ }^{28 .}$

En síntesis, la crisis afectó a los más pobres y creó nueva pobreza derivada de la suba de precios de productos de primera necesidad y la desocupación creciente. Ante esta situación se observa un interés incrementado en el ámbito municipal por la situación económica y diversas medidas fueron puestas en práctica durante todo el periodo para paliar esta coyuntura.

Todas estas medidas, perseguian el mismo objetivo: llevar algo de auxilio a quienes más lo necesitaron durante un tiempo de crisis extenso y persistente que con oscilaciones y variaciones en el grado de intensidad se manifestó en todo el periodo 29 .

26 Archivo Histórico Municipal de Tandil (en adelante AHMT), Actas del Concejo Deliberante Libro 1259 (1909-1914), 10/5/1913, f. 139.

27 AHMT, Actas del Concejo Deliberante, Libro 1260 (1914-1921), 26/4/1915, f. 35.

28 Se habian creado en junio de 1919. ACDA, Libro de Actas (27/11/1911 al 2/11/1919), 18/6/1919, f. 254.

29 Por ejemplo, en Tandil se reforzó el rubro presupuestario para beneficencia y la Intendencia siguió tomando algunas medidas como la venta al costo de azúcar. AHMT, Actas del Concejo Deliberante, Libro 1260 (1914-1921), 20/11/1918, f. 258 y 25/9/1920, f. 428, entre otros. En Azul, se formó en 1919 en el seno del Concejo la "Comisión pro abaratamiento" de cara a tomar nuevas medidas y avanzaron en la idea de municipalizar la venta de ciertos productos como pan, carne, leche, arroz, y fideos. ACDA, Libro de Actas (27/11/1911 al 2/11/1919), 5/2/1919, f.217.

\section{anuario.}


A pesar de que la aproximación a estas fuentes municipales puede ofrecernos una imagen de dirigencias sensibilizadas por la pobreza y las peripecias para sobrevivir de los sectores empobrecidos en tiempos de crisis, no podemos decir lo mismo sobre sus acciones en pro del socorro de la infancia. Si bien las distintas iniciativas llevadas adelante antes mencionadas nos muestran un Estado local dispuesto a intervenir para paliar diversas situaciones vinculadas a la pobreza en aumento, los menores de edad no estuvieron en su agenda.

Las excepciones a esta generalidad la encontramos en alguna predisposición personal de concejales como Francisco Yanzi quien en 1919, alarmado por la cuestión de la infancia pobre y mendicante en el partido de Azul, propuso que la oficina de obras públicas

\begin{abstract}
“(..) formule un presupuesto del costo aproximado y confeccione los planos respectivos para la fundación en el Azul de dos reformatorios para menores vagos $y$ mendigos; uno de tendencia industrial con talleres adecuados para albergar cincuenta menores y otro consistente en una colonia agricola en las afueras de la ciudad también para cincuenta niños (...)"3o.
\end{abstract}

No sabemos con certeza qué sucedió con esta iniciativa y en cambio sí es posible afirmar que en el ámbito local persistió (e incluso se incrementó), la política estatal de subsidiar instituciones privadas gestionadas por mujeres que se encargaban de la infancia ${ }^{31 .}$

En parte, podemos explicar esto porque, como ha sostenido Suriano, la cuestión social (por ejemplo el tema de la pobreza) fuera del marco de la higiene y la salud no parecía ser percibida por los gobernantes en toda su magnitud. Así dice el autor citado que esto se debía a la concepción liberal predominante entre los grupos gobernantes, tratándose de “(...) un condicionamiento de carácter filosófico relacionado con la concepción de una sociedad minima” (Suriano, 2001: 129-130). Por ello, confiaban a la Caridad la resolución de los problemas, brindando solo subsidios. A estas limitaciones filosóficas que alude Suriano haciendo foco en la

30 Ibidem, 7/5/1919, f. 248. También recogía esta inquietud El Ciudadano, aplaudiendo la iniciativa. El Ciudadano, Azul, Reformatorio de Menores. Proyecto de ordenanza del concejal Yanzi, 9/5/1919.

31 Tal fue así que en Azul, el presupuesto para 1919, preveía aumentos sensibles en las subvenciones otorgadas a las instituciones a favor de la infancia, en relación al proyectado para 1917. ACDA, Libro de Actas (27/11/1911 al 2/11/1919), 31/12/1916 f. 76 y 20/12/1918, f. 189. En el caso de Tandil los presupuestos muestran una disminución en la subvención acordada al asilo de huérfanas (para 1914 se proyectaba en $\$ 100$ y para 1917 se propuso una quita del $50 \%$ ) como también se hizo con otras instituciones. Sin embargo, aumentó la cantidad de instituciones subsidiadas entre 1915 y 1919 , lo cual indica que se repartieron recursos escasos entre mayor número de postulantes. Esto habla sin embargo de una continuidad en la práctica de acompañar de este modo antes que tomar en sus manos acciones directas. AHMT, Actas del Concejo Deliberante, Libro 1259 (1909-1914), 29/12/1914, f.202; Libro 1260 (1914-1921), 29/12/1916 f. 154 y 30/12/1918, f. 262.

\title{
anuario.
}


cuestión obrera, entiendo que debemos sumar que en materia de infancia, ese Estado contaba con otras agencias para auxiliarlo en la resolución de problemas que cada vez parecian ser más urgentes. Estas instituciones fueron las que supieron hallar soluciones acordes a las necesidades del momento, flexibilizando y ampliando sus políticas asistenciales. Fue así que mientras los municipios desplegaban nuevas intervenciones sobre los sectores empobrecidos, las comisiones de benefactoras que venían desempeñando labores de socorro sobre los sectores más vulnerables de la infancia desde los tramos finales del siglo XIX, fueron las que renovaron y ampliaron sus respuestas a las demandas de la prensa y de la sociedad, como veremos más adelante.

\section{El Patronato Provincial de Menores: una solución a mitad de camino}

Así como llegando a los años 20, el concejal Yanzi en Azul alzaba su voz para sostener que era el Estado municipal quien debía tomar en sus manos la solución a la cuestión de los menores de edad y su formación, había sido en las altas esferas de la política provincial donde tempranamente ideas similares habian surgido con un éxito distinto.

José Inocencio Arias gobernador de la provincia de Buenos Aires entre 1910 y 1912 , manifestó ciertas preocupaciones por la situación social de este sector al poco tiempo de arribar al poder. Esto tuvo como resultado la sanción en 1910 de la Ley de Patronato de Menores de la provincia de Buenos Aires, que preveía la creación de una institución modelo destinada a dar albergue y formar para el trabajo a la mayor cantidad de niños y niñas posible y que por diversas razones estaban a cargo de los Defensores de Menores. Si bien y como sostiene otro trabajo, la promoción de una institución como esta respondía a la convicción de que era necesario impulsar una manera más moderna de atender a estos problemas y estaba acorde con inquietudes que comenzaban a manifestarse al respecto, la muerte del gobernador y los avatares politicos posteriores, demoraron la concreción de la ley (de Paz Trueba, 2020). Habría que esperar a la segunda gobernación de Ugarte ${ }^{32}$ para ver algunos progresos, como la propuesta de instalar el Patronato en una fracción de tierra fiscal ubicada en la sección Abasto de la ciudad de La Plata. En la práctica, lo que funcionó fue un espacio provisorio que había sido reservado también por el gobierno de Ugarte para refugio de niños ubicado en la calle 6 número 1274 de la ciudad, y cuyo desempeño reglamentó el gobierno de la Intervención ${ }^{33}$. José Camilo Crotto, el gobernador siguiente, no mostró gran interés en concretar la instalación del Patronato en su

\footnotetext{
32 Entre mayo de 1914 y abril de 1917.

33 Archivo de la Legislatura de la provincia de Buenos Aires (en adelante ALPBA), Registro Oficial de la Provincia de Buenos Aires, Año 1917, Tomo 2, julio a diciembre, La Plata, Taller de Impresiones Oficiales, 1919, Intervención Nacional, Departamento de Gobierno, Decreto N619, 4/9/1917, p. 634 a 640.

La provincia estuvo intervenida por el gobierno nacional entre abril de 1917 y mayo de 1918 con la intención manifiesta de sanear las instituciones erosionadas por las políticas caudillistas y el fraude electoral instauradas por los gobiernos de signo conservador.
}

\section{anuario.}


propio edificio. En junio de 1920, a poco de renunciar al gobierno a

causa de presiones políticas, Crotto puso la piedra fundamental del que sería el edificio definitivo de la Institución que por entonces, siguió desarrollando sus tareas en el local anterior que no reunía las condiciones necesarias para hacer realidad el proyecto que la ley preveía. Además de que allí se albergaban solo unos 60 varones, las reducidas dimensiones del lugar no permitian recoger a las menores de sexo femenino 34 , y no contaba con espacio suficiente para los talleres que constituían la piedra angular del Patronato pensado para asilar, pero sobre todo para formar.

Los problemas que este proyecto encontró en la práctica para llevarse a cabo de manera completa, persistieron. Fundamentalmente, no alcanzó para dar solución, como ampulosamente se pregonó en su origen, al grave problema de la mendicidad y el abandono infantil de la ciudad capital y también de los partidos de la provincia que tendrían la posibilidad de enviar allí a menores que no encontraran asilo en sus lugares de origen.

Tal como detallaba en su Memoria de 1922-23 el Ministro del Interior en relación al movimiento de la Defensoría General de la provincia, de los 1109 menores de edad que habian sido atendidos por ella, solo 297 habían encontrado lugar en el patronato. Los restantes habian sido repartidos en diferentes establecimientos carcelarios y asilares como el Buen Pastor, y muchos de ellos (285 mujeres y 76 varones) en casas de familia ${ }^{35 .}$

No obstante esas dificultades reconocidas por los mismos funcionarios, y criticadas por la prensa platense, esos "ensayos" del Patronato constituyeron en la práctica una respuesta concreta dada desde el Poder Ejecutivo de acuerdo con la Ley de 1910. Aunque incompletos y tardios permitieron poner manos a la obra, y según el mismo Ministro detallaba, se habían tomado durante ese año múltiples medidas para mejorar las condiciones internas tanto de higiene como de funcionamiento de la institución.

Si en la ciudad capital la cuestión del espacio asilar era un problema de dificil solución, y el Patronato había sumado posibilidades dentro de un entramado complejo y persistente de colaboración privada y religiosa, en el interior provincial,

\footnotetext{
${ }^{34}$ Medidas al respecto se tomaron en los tramos finales del gobierno de Crotto. Por medio de un decreto provincial estableció el alojamiento de mujeres en el local de la calle 6, encargando de la administración, educación, cuidado y vigilancia de las menores a la Congregación de Nuestra Señora de la Misericordia. ALPBA, Registro Oficial de la Provincia de Buenos Aires, Año 1920, Tomo 1, enero a junio, La Plata, Taller de Impresiones Oficiales, 1924, Departamento de Gobierno, decreto No 159, 23/3/1920, p. 253254. Sin embargo, tras la renuncia de Crotto aún no se había efectivizado (de Paz Trueba, 2020).

35 ALPBA, Memoria del Ministerio de Gobierno de la provincia de Buenos Aires, periodo 1922-1923, La Plata, 1924 (digitalizado por Biblioteca de la Legislatura).
} 
las instituciones confesionales y las casas de familia, eran las soluciones mayores y únicas.

Mientras que los gobernadores de diversos signos políticos intentaron al menos resolver la cuestión de la infancia primero con la creación y más tarde con el perfeccionamiento del Patronato, que se sumaba a las otras opciones, en los espacios locales, estas acciones oficiales siguieron estando reducidas al otorgamiento de subvenciones, siempre insuficientes.

\section{Acciones por la infancia: actores e iniciativas privadas}

Hacia 1926, la Congregación Hijas de Maria de Tandil, una agrupación laica de mujeres ligadas a la Iglesia católica local, veía cada vez más cerca la concreción de un anhelado proyecto que habian puesto en marcha varios años atrás: la erección de un hogar escuela para niños de sexo masculino, percibido por la comunidad, tal como la prensa local religiosa e independiente transmitía por entonces, como una necesidad apremiante 36.

Habida cuenta de que el proyecto pretendia no solo recoger y asilar de manera permanente a aquéllos que fueran en verdad huérfanos y/o abandonados sino también tomar en calidad de externos a quienes no tuvieran donde pasar el día, la prensa sostenía acaloradamente que la población debía apoyar económicamente la tarea ${ }^{37}$. Con este mecanismo más flexible de asilo y contención, se pondría fin según se anunciaba, a un gran problema: el vagabundeo infantil originado no solo en una necesidad real de mendigar para obtener el sustento sino también en la desidia familiar 38 .

Desde fines del siglo XIX la Iglesia católica había manifestado preocupaciones en torno a la cuestión social a través de su primera encíclica social, Rerum Novarum, emitida por León XIII en 1891. Allí se recogian las preocupaciones que generaban las demandas de las clases trabajadoras y se diagnosticaban problemáticas que presentaban las sociedades industriales y la modernidad política. Ante el peligro que desde esta óptica representaban las ideas y prácticas del comunismo, el anarquismo y el socialismo en relación a la salida de los problemas del proletariado, la Iglesia propugnaba formas distintas de intervenir para morigerar los problemas sociales de manera conjunta a los Estados y a sectores católicos.

\footnotetext{
36 El Eco de Tandil, Tandil, En bien de la niñez, 1/3/1923. La Revista, Tandil, Asilo Hogar de Varones. Algunas consideraciones, 24/5/1924; Asilo de Varones, 31/7/1925 y Apertura del Asilo de Varones Brigadier Gral. Martín Rodríguez, 27/11/1925, entre otros.

37 El Eco de Tandil, Tandil, Pro niños pobres, 13/12/1923. La Revista, Tandil, Asilo de Varones, $31 / 7 / 1925$, cit.

38 El Eco de Tandil, Tandil, Asilo Hogar del niño, 22/1/1922.
}

\section{anuario.}


A mediados de la segunda década del siglo XX, la conflictividad social y el problema obrero eran fuente de preocupación en Argentina, en el marco de la crisis económica. En este sentido, y a tono con aquéllos planteos de Rerum Novarum, se comenzaron a buscar otras maneras desde la Iglesia en pos de avanzar en nuevas estrategias de apostolado 39 .

Impulsar con mayor fuerza el catolicismo social tenía un doble propósito: evitar la desmoralización de la sociedad a causa de las ideas de izquierda y por otro lado, como parte de un propósito preventivo, apuntalar a los sectores menos favorecidos y más castigados por la crisis, especialmente obreros, para evitar que se vieran seducidos por esas ideas disolventes (Vidal y Blanco, 2010)40. No alcanzaba con el ejercicio de la caridad al modo tradicional, había que avanzar en modo estratégico y organizado en conjunto con el Estado.

En ese marco de interés y tácticas específicas del catolicismo por llegar a diversos ámbitos de la sociedad, se habilitaron nuevos espacios de acción femenina en las asociaciones civiles “(...) otorgando roles más activos para la mujer a través de la acción social católica y su participación en las viejas y nuevas organizaciones del laicado" (Mauro, 2014: 242) ${ }^{41}$.

Desde fines de siglo XIX tanto en Azul como en Tandil habian sido las instituciones privadas lideradas por mujeres las que habian atendido situaciones de carencias y precariedad de diverso tipo. Muchas de ellas eran de corte religioso como las Damas de Caridad, que habian fundado a fines del siglo XIX asilos para niñas huérfanas 42. Asimismo en Azul, otra agrupación católica vinculada en torno a la Pía Unión de San Antonio, pensó varios años después en la necesidad de asilar y formar para el trabajo

\footnotetext{
39 Entre ellas tuvieron centralidad la reactivación del catecismo y una serie de actividades recreativas y de sociabilidad que se sumaban a la enseñanza de la doctrina de cara a reactivar la vida parroquial (Mauro, 2014).

40 Esta perspectiva no carecía de fisuras dado que dentro del catolicismo existían diversas tendencias, que si bien compartían el rechazo a la modernidad (representada tanto por el liberalismo como por el comunismo) así como el proyecto de llevar el catolicismo a todas las esferas de la vida social y política, diferian en los modos para ello. Las tensiones entre esas dos formas de pensar dentro del nuevo catolicismo de los primeros años del siglo XX hicieron imposible unificar las acciones del laicado bajo los lineamientos de la jerarquía. Esa unificación no se logró en los años 20 entre otras cosas por las resistencias de las iniciativas autónomas que desde comienzos de siglo habían surgido para atender cuestiones sociales. Recién se habría conseguido con la fundación de Acción Católica en los años '30 (Di Stefano y Zanata, 2009; Vidal y Blanco, 2010).

41 Solo por mencionar algunas de esas instituciones podemos referir a la rama femenina de la Asociación de Artesanos de San José de Córdoba (Vidal, 2016) y las Damas de Caridad de San Vicente de Paul y las Conferencias de San Vicente de Paul de la ciudad de Buenos Aires (Tossounian, (2015).

42 Se trataba de las Damas de Caridad del Sagrado Corazón de Jesús. Aunque ambas tenían mismo nombre y dinámica similar, no mantenían relaciones entre sí. Las de Azul habían establecido el asilo en 1886 y las de Tandil en 1897.
} 
a los niños de sexo masculino. Esas preocupaciones dieron origen a la fundación en 1911 del Asilo San Antonio.

En los asilos para niñas, la asistencia a la escuela que funcionaba anexa a los mismos así como la instrucción en tareas consideradas propias de su sexo (como la costura y el bordado) eran objetivos perseguidos por las benefactoras. Incluso en ocasiones, que aunque escasas fueron muy significativas por su sentido, algunas internas pudieron obtener becas para formarse como maestras en la Escuela Normal de la localidad (de Paz Trueba, 2014). En el caso de la institución para varones y acorde con ideas dominantes que irian tomando fuerza a medida que transcurrían los primeros años del siglo XX, la educación para el trabajo se pensaba anudada al asilo como solución para que esos chicos y chicas pudieran insertarse a la sociedad como "elementos útiles" al salir de ellos (Sosensky, 2008; Stagno, 2010). En el asilo de varones de Azul conforme pasaban los años, se fue acrecentando la labor en este aspecto. Durante la década de 1920, lograron consolidar su obra gracias a reformas edilicias introducidas, que permitieron alojar mayor número de niños así como la instalación de más talleres. Además de aumentar el número de asilados, pudieron incorporarse también internos en calidad de pupilos, así como externos (de Paz Trueba, 2017). El número de chicas asiladas creció también en Tandil al ritmo de una demanda en ascenso. En los años 20 las Damas de Caridad que lo gestionaban llegaron a tener 60 internas ${ }^{43}$.

También fue durante esos años 20 cuando los niños de sexo masculino recibieron en Tandil atención por parte de la mencionada Congregación Hijas de María. Estas mujeres que desde los primeros años del siglo XX trabajaban entregando ropa a los más pobres de la ciudad, prendas que ellas confeccionaban en un taller de costura propio, ${ }^{44}$ decidieron atender esa enorme demanda de ayuda que pesaba en relación a los niños varones. Si bien la fundación del Hogar de Varones Martín Rodríguez de Tandil puede interpretarse como la continuidad de una politica anterior, debemos analizar los matices ya que se dio en un contexto diferente al que habian visto nacer otras instituciones locales de características similares.

Fue así que estimuladas por el presbítero Julio María Chienno, representante local del catolicismo social, decidieron instalar un asilo para niños y jóvenes de sexo masculino que preveía como señalaba El Eco, albergar

“(...) en carácter de asilados permanentes a los varones huérfanos o desamparados

(...) servirá de hogar o asilo diurno para todos los niños y niñas separadas entre sí que la policía sorprenda pidiendo limosna por las calles y plazas de la ciudad y

\footnotetext{
43 La Revista, Tandil, A beneficio del Asilo de Huérfanas, 11/11/1922.

44 El taller fue inaugurado y bendecido por el obispo Monseñor Francisco Alberti el 8-12-1905. Archivo Parroquia de Tandil, Fondo Hijas de Maria, Acta de Constitución.
} 
suburbios (...)se les proporcionará comida y ropa conveniente; se les

llevará en corporación hasta la escuela del Estado más próxima(...)”. 45

Tenian entre manos un proyecto ambicioso y una tarea ardua pero que era bienvenida por la prensa no solo como tarea humanitaria sino también porque acorde con las preocupaciones del momento, “(...) con este Hogar Asilo se conseguirá eliminar directamente de nuestras calles a tantos niños y niñas harapientos y sucios que piden limosna(...)"46. Recién en enero de 1926, luego de años de planearlo y arduos esfuerzos por reunir recursos, lograron poner en funcionamiento efectivo el asilo que ya en marzo, entre externos e internos, albergaba o socorría gratuitamente a 40 niños, resultando ya insuficientes los espacios 47 . Una modalidad que como vemos, diferentes asociaciones de la zona incorporaron por entonces ante demandas diversificadas y espacios escasos, lo que permite acercarnos a respuestas más elásticas y renovadas por parte de las benefactoras, como la prensa reclamaba, adaptada a las necesidades que los nuevos tiempos planteaban en materia de asistencia ${ }^{48 .}$

Aquellas funciones tradicionales que desde fines del siglo XIX las mujeres habian desempeñado en el espacio público de la mano de la extensión de sus funciones maternales y de cuidado, encontró en este marco un nuevo auge. Las benefactoras contaban en estas comunidades con el prestigio ganado durante décadas por sus acciones por los pobres y en especial por la infancia. Se sumaba a esto, su pertenencia a congregaciones laicas de raigambre católica que de la mano de un catolicismo social reactivado reforzó su lugar para atender situaciones como las cuestiones de infancia 49 . Las acciones por este colectivo encontraron allí un terreno fértil y se intensificó la participación de las mujeres en el movimiento católico ya que “(...) La apertura de este tipo de espacios religiosos de actuación contribuía también, a los ojos de los católicos, a que las mujeres se mantuvieran alejadas de los peligros y las tentaciones del mundo moderno" (Bracamonte, 2017: 185).

\section{Consideraciones finales}

\footnotetext{
45 El Eco de Tandil, Tandil, Asilo Hogar del niño, 22/1/1922, cit.

46 Idem.

47 La Revista, Tandil, Asilo de Varones, 5/3/1926 y Apertura del asilo de varones brigadier Gral. Martín Rodríguez. Algunas consideraciones, 1/1/1926.

48 El Asilo de Ancianos, también gestionado por las Damas de Caridad tenía modalidades similares. Si bien este es objeto de estudio en otro trabajo en progreso, se menciona aquí porque sirve para dar cuenta de la expansión y ampliación de formas de asilo y socorro implementadas por la obra de esta asociación católica.

49 Algo que, como ha demostrado Cecilia Tossounian (2015), no se agota en los años 20 sino que puede observarse en los años 30 cuando se dio un mayor intervencionismo estatal en materia de infancia y familia, e incluso en los años 40.
} 
Desde la segunda década del siglo XX crecieron los discursos que señalaban la responsabilidad estatal en relación a diversos aspectos que hacian a la cuestión social. Y si bien gran parte de estos hacían hincapié en la necesidad de controlar para preservar el orden social, también es posible observar de manera recurrente algunos desplazamientos en la manera de entender la función del Estado. Según se señalaba cada vez con mayor insistencia en el periodo estudiado, se consideraba que este era responsable en materia social y de asistencia a la infancia pobre y abandonada o vagabunda.

Las fuentes abordadas en este trabajo permiten afirmar que si bien el diagnóstico y las demandas de los discursos son transversales tanto en documentos estrictamente locales como en otros de dimensión provincial, las soluciones puestas en práctica muestran algunas diferencias. Es así que se sostiene que mientras en ámbitos municipales, se observan algunas innovaciones en relación a las intervenciones estatales sobre la pobreza, ampliando el espectro de lo que tradicionalmente se había hecho, se trató en todo caso de medidas coyunturales pensadas para aliviar a la clase obrera.

Sin embargo, no hubo una acción institucional nueva o más orgánica en relación a los niños y niñas pobres.

En cambio, donde sí encontramos atisbos de una política cambiante, es en el ámbito provincial. Allí, el Patronato de Menores, aunque insuficiente por su magnitud, buscó poner en práctica una manera nueva, en tanto institución de financiamiento totalmente estatal, de solucionar el problema de la infancia abandonada de la provincia. Es además la muestra cabal de un Estado que intentó tomar en sus manos la solución.

Mientras tanto, los años 20 fueron prolíficos en un accionar femenino renovado que encontró nuevos espacios para desplegarse, ante demandas crecientes. En un contexto de necesidades acentuadas, las mujeres católicas encontraron nuevos lugares para desempeñar una labor en la que tenían décadas de experiencia en la región estudiada. Si bien los discursos fueron enfáticos al proponer nuevas maneras de resolver un problema que veían en aumento, para implementarse debían contar con recursos que en un momento de crisis el Estado tenía en escasas cantidades y debió usar para atender otras problemáticas para las que no había una estructura organizada como en cambio sí existía para el caso de los y las menores de edad. Sumado a esto y como se muestra en otra parte, los vaivenes políticos dejaron muchas veces las soluciones de la infancia en manos privadas o en otras ocasiones llegaron más tarde y con menor impacto del buscado inicialmente (de Paz Trueba, 2020).

No se trató solo, como bien ha sostenido Suriano, de la preeminencia de una concepción imperante sobre la necesidad de un Estado liberal mínimo entre quienes 
debían poner en práctica nuevas maneras de atender a la infancia.

Además de esto, estamos frente a representantes del Estado que compartían esa matriz de pensamiento sobre quiénes eran los actores que debían ocuparse, con la misma comunidad que lo demanda. Las mujeres que se desempeñaron en las instituciones de beneficencia católica y la Iglesia que reclamó legislación laboral al Estado, creían que ellas eran parte de la elite moral que debía tomar en sus manos esas funciones.

En suma, la infancia fue un campo sobre el que se plantearon problemas, soluciones, se disputaron sentidos y prácticas. Pensar esos derroteros en sentido histórico, ayuda finalmente no solo a entenderlos en ese contexto situado, sino que brinda también una mejor comprensión sobre la trayectoria de las intervenciones en entornos de desigualdad. Las prácticas y representaciones actuales sobre la infancia, tienen una larga historia. Reflexionar sobre su construcción pretendió también ser un aporte de este trabajo.

\section{Bibliografia}

Allemandi, C. (2017). Sirvientes, criados y nodrizas. Una historia del servicio doméstico en la ciudad de Buenos Aires (fines del siglo XIX y principios del XX). Buenos Aires: Teseo-Universidad de San Andrés.

Aversa, M. M. (2015). Un mundo de gente menuda. El trabajo infantil tutelado, ciudad de Buenos Aires, 1870-1920 (Tesis de Doctorado inédita). Facultad de Filosofia y Letras, Universidad de Buenos Aires.

Billorou, M. J. (2010). Los comedores escolares en el Interior argentino (19301940). Discursos, prácticas e instituciones para el apoyo a los escolares necesitados. En L. Lionetti y D. Míguez (comps.); Las infancias en la historia argentina. Intersecciones entre prácticas, discursos e instituciones (18901960).Rosario: Prohistoria.

Bonaudo, M. (2006). Cuando las tuteladas tutelan y participan. La Sociedad Damas de Caridad (1869-1894). Signos Históricos (8).

Bracamonte, L. (2012). Mujeres benefactoras en el sudoeste bonaerense argentino: el caso del Patronato de la Infancia de Bahía Blanca, 1906-1931. Historelo (4). 
Bracamonte, L. (2017). "Damas" y asistencia social: las comisiones de cooperadoras salesianas en Bahía Blanca durante la década de 1920. En M. Cernadas, M. de las N. Agesta y J. López Pascual, (coords.); Amalgama y distinción. Culturas politicas y sociabilidades en Bahía Blanca. Bahía Blanca: EdiUNS.

Dalla-Corte Caballero, G. y Piacenza, P. (2006). A las puertas del Hogar: madres, niños y Damas de Caridad en el Hogar del Huérfano de Rosario (1870-1920). Rosario: Prohistoria.

de Paz Trueba, Y. (2010). Mujeres y esfera pública: la campaña bonaerense entre 1880 y 1910. Rosario: Prohistoria.

de Paz Trueba, Y. (2014). El trabajo infantil en el centro y sur de la provincia de Buenos Aires. Niñas y niños a fines del siglo diecinueve y principios del veinte. Mundos do Trabalho 6 (12).

de Paz Trueba, Y. (2017). Asilos, infancia y trabajo: la campaña bonaerense a fines del siglo XIX y comienzos del XX. Revista Andes (28).

de Paz Trueba, Y. (2020). El Patronato Provincial de Menores: iniciativas por la infancia pobre en la Provincia de Buenos Aires (1917-1921). Secuencia (106).

Di Stefano, R. y Zanata, L. (2009). Historia de la Iglesia Argentina. Desde la conquista hasta fines del siglo XX. Buenos Aires: Sudamericana.

Eraso, Y. (2009). Maternalismo, religión y asistencia: la Sociedad de Señoras de San Vicente de Paul en Córdoba, Argentina. En Y. Eraso (comp.); Mujeres y asistencia social en Latinoamérica, siglos XIX y XX. Argentina, Colombia, México, Perú y Uruguay. Córdoba: Alción editora.

Freidenraij, C. (2016) La niñez desviada. La tutela estatal de niños pobres, huérfanos y delincuentes. Buenos Aires, c. 1890-1919. (Tesis de Doctorado inédita). Facultad de Filosofia y Letras, Universidad de Buenos Aires.

Fuentes, L. (2016). Conservadores y radicales en el interior bonaerense. Ayacucho, Azul, Lobería y Tandil, 1910-1943. (Tesis de Doctorado inédita). Facultad de Ciencias Humanas, Universidad Nacional del Centro de la Provincia de Buenos Aires, Tandil, Argentina.

Guy, D. (2011). Las mujeres y la construcción del Estado de Bienestar. Caridad y creación de derechos en Argentina. Buenos Aires: Prometeo.

Lida, M. (2015). Historia del catolicismo en Argentina entre el siglo XIX y el XX. Buenos Aires: Siglo XXI. 
Lvovich, D. y Suriano, J. (eds.) (2006). Las politicas sociales en perspectiva histórica. Argentina, 1870-1952. Buenos Aires: Prometeo.

Mauro, D. (2014). La "mujer católica" y la sociedad de masas en la Argentina de entreguerras. Catolicismo social, consumo e industria cultural en la ciudad de Rosario (1915-1940). Hispania Sacra, LXVI, (133). Recuperado de http://hispaniasacra.revistas.csic.es/index.php/hispaniasacra/article/view/3 $85 / 386$

Moreyra, B. (2009). Cuestión social y politicas sociales en la Argentina. La modernidad periférica: Córdoba, 1900-1930. Bernal: Universidad Nacional de Quilmes.

Ortiz Bergia, M. J. (2009). De Caridades y Derechos. La construcción de politicas sociales en el interior argentino. Córdoba (1930-1943). Córdoba: CEH.

Pita, V. (2012). La Casa de las Locas. Una historia social del Hospital de Mujeres Dementes, Buenos Aires, 1852-1890. Rosario: Prohistoria.

Remedi, F. (2017). Pululan por nuestras calles infinidad de menesterosos. Miradas y concepciones sobre la mendicidad. Córdoba (Argentina), en el tránsito del siglo XIX al XX. Historia 396 (2).

Remedi, F. (2019). Miradas sobre la mendicidad infantil en la ciudad de Córdoba en las primeras décadas del siglo XX. Páginas (27). Recuperado de http://revistapaginas.unr.edu.ar/index.php/RevPaginas.

Rojas Novoa, M. S. (2018). La protección de la infancia en América: alcances de una problematización histórica. Ponencia presentada en 5 tas Jornadas de Estudios sobre la Infancia, Buenos Aires. Recuperado de https://www.aacademica.org/5jornadasinfancia/13.

Sosensky, S. (2008). Un remedio contra la delincuencia: el trabajo infantil en las instituciones de encierro de la ciudad de México durante la posrevolución. Asclepio. Revista de historia de la medicina y de la ciencia (2).

Stagno, L. (2010). Una infancia aparte. La minoridad en la provincia de Buenos Aires. Buenos Aires: FLACSO - Libros Libres.

Tossounian, C. (2015). Las Asociaciones Femeninas y la Emergencia de un Estado Social: La Protección a la Maternidad y a la Infancia (Buenos Aires 19201940). Estudios Sociales del Estado 1 (2). Recuperado de http://estudiossocialesdelestado.org/index.php/ese/article/view/56 
Mujeres católicas y Estado en torno a la pobreza y la infancia: viejas y nuevas intervenciones en la provincia de Buenos Aires, 1913-1926

Vidal, G. y Blanco, J. (comps.) (2010). Catolicismo y politica en Córdoba, siglos $X I X$ y XX. Córdoba: Ferreyra editor.

Vidal, G. (2016). El Nuevo Catolicismo en Córdoba durante las primeras décadas del siglo XX. En Anuario (28). Recuperado de http://anuariodehistoria.unr.edu.ar/ojs/index.php/Anuario.

Zapiola, C. (2019). Excluidos de la niñez. Menores tutela, estatal e instituciones de reforma. Buenos Aires, 1890-1930. Buenos Aires: UNGS.

Recibido: 23 de enero de 2020 Aceptado: 10 de marzo de 2020 Versión Final: 22 de abril de 2020 